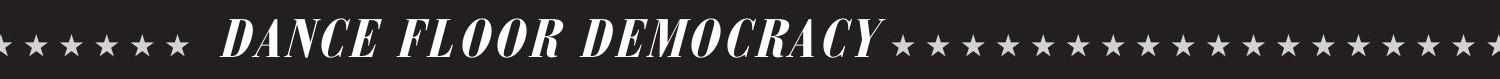




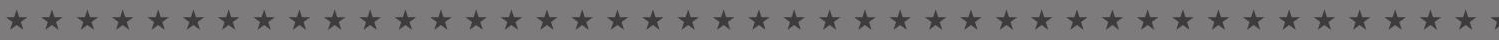

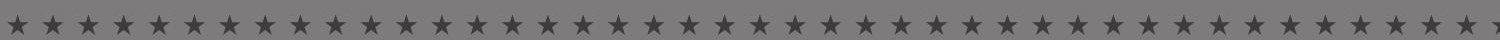

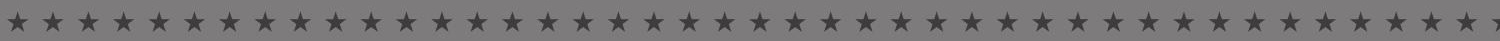

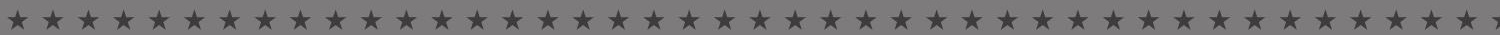

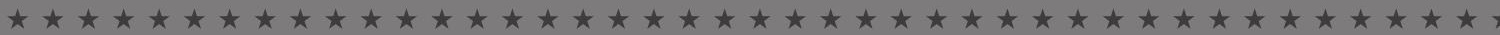

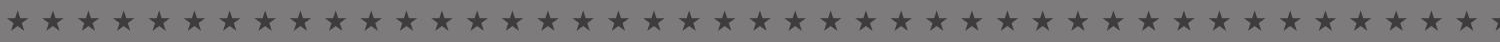

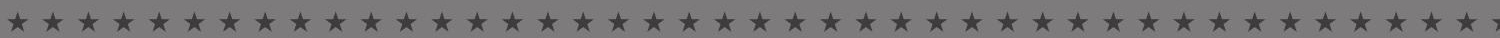

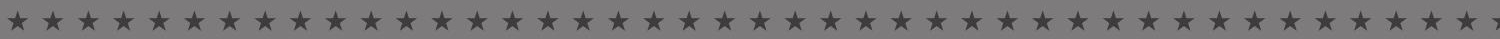

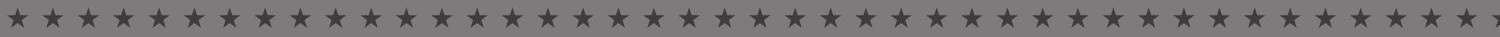

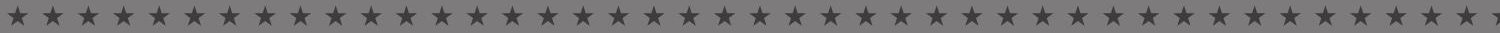

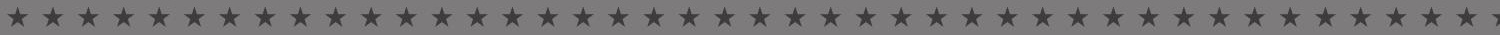

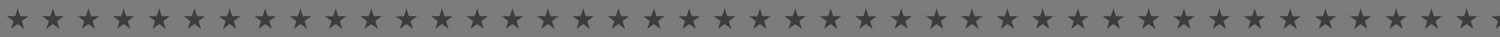

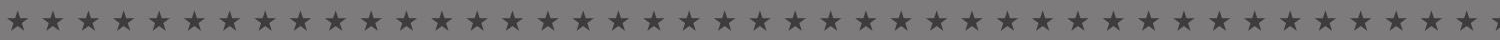

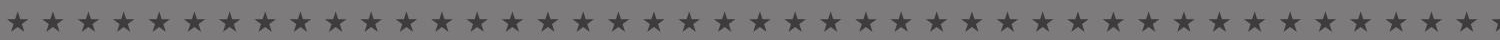

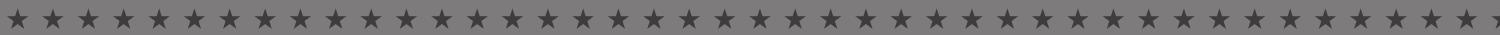

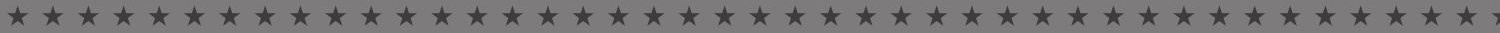

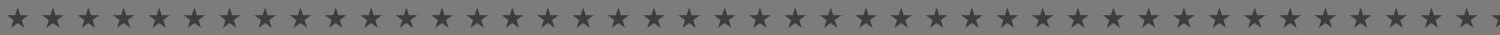

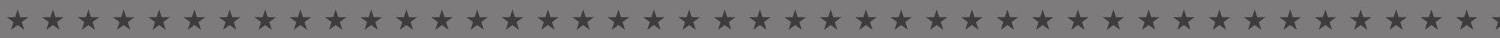

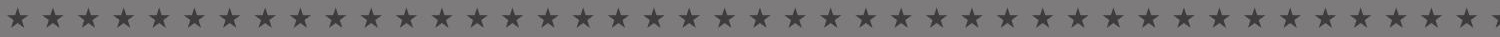

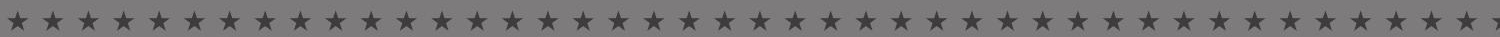

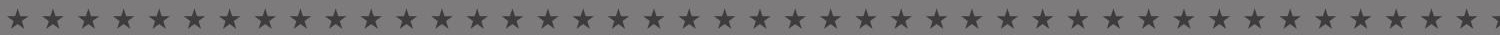

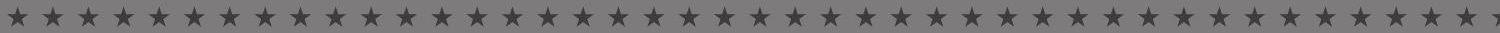

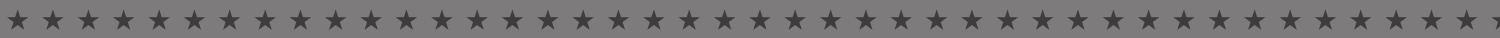

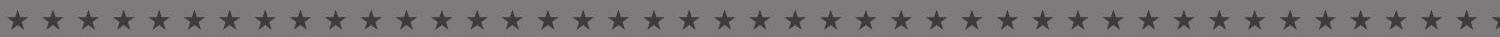

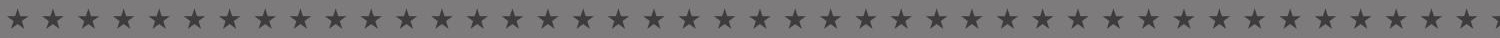

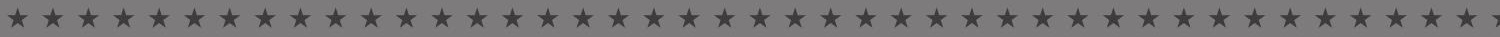

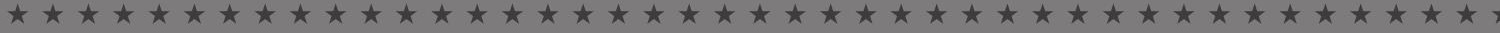

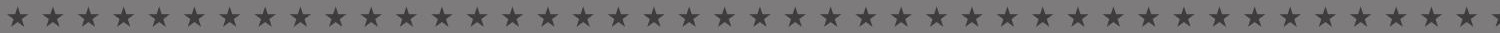

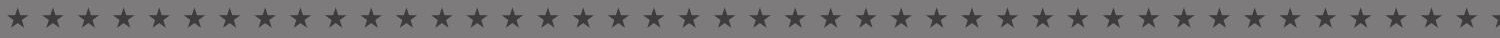

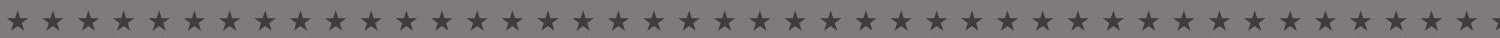

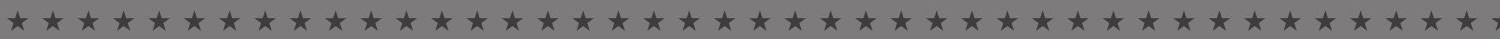

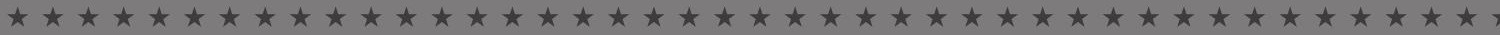

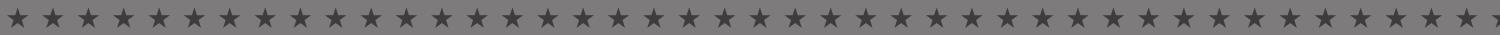

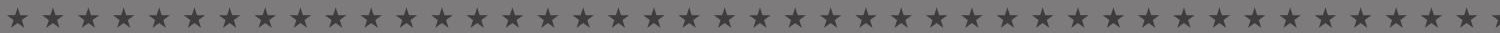

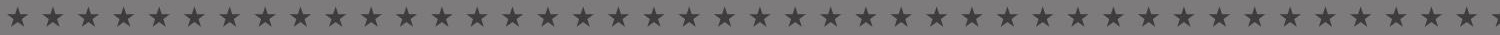

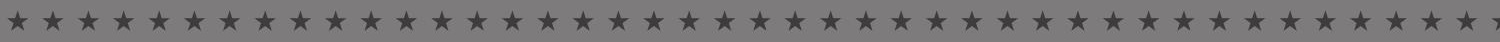

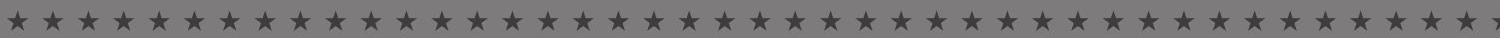

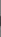

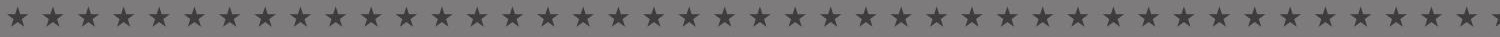

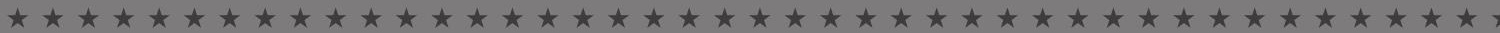

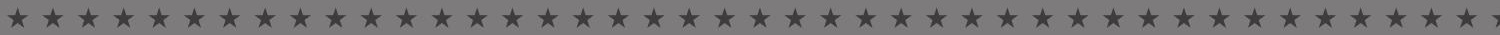

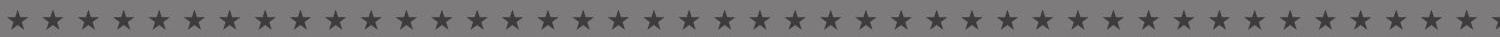

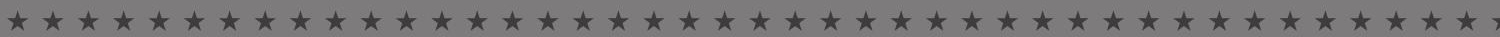

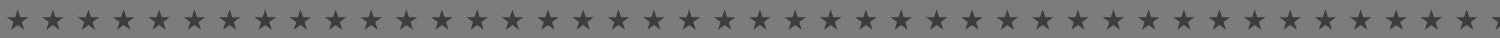

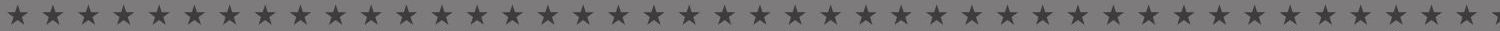

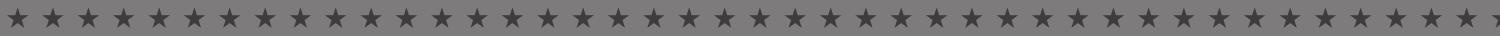

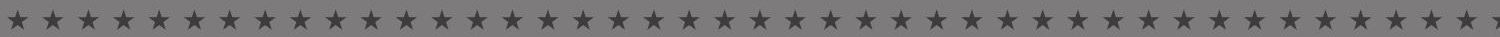

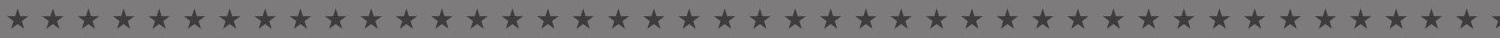

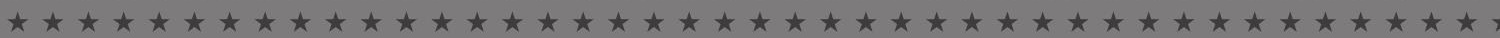

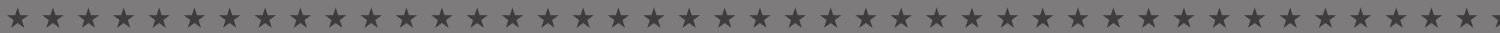

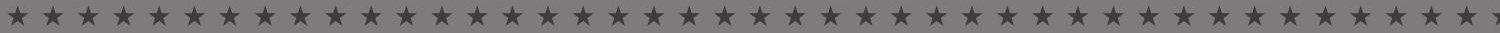

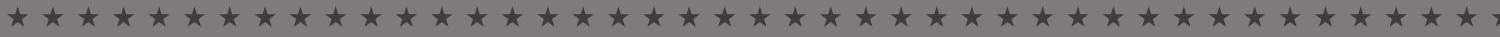

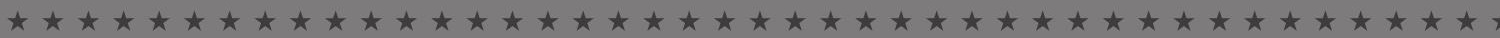

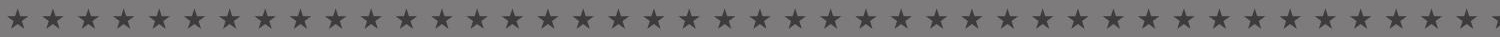

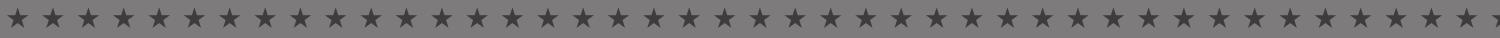

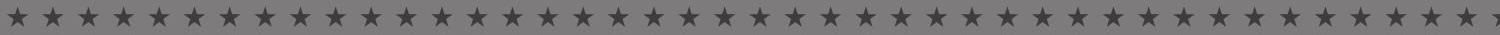

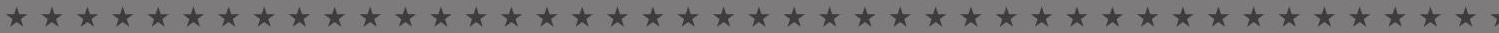




\section{DANCE FLOOR DEMOCRACY}

THE SOCIAL GEOGRAPHY OF MEMORY AT THE HOLLYWOOD CANTEEN 
(C) 2014 Duke University Press

All rights reserved

Printed in the United States of America on acid-free paper $\infty$

Designed by Heather Hensley

Typeset in Minion Pro by Westchester Book Group

Library of Congress Cataloging-in-Publication Data

Tucker, Sherrie, 1957-

Dance floor democracy : the social geography of memory at the Hollywood Canteen / Sherrie Tucker.

pages $\mathrm{cm}$

Includes bibliographical references and index.

ISBN 978-0-8223-5742-1 (cloth : alk. paper)

ISBN 978-0-8223-5757-5 (pbk. : alk. paper)

1. Hollywood Canteen. 2. World War, 1939-1945-Social aspectsUnited States. 3. Memory-Social aspects-United States. 4. Los Angeles (Calif.)-Social conditions-2oth century. 5. Dance-Social aspects-California-Los Angeles-History-2oth century. I. Title. D744.7.U6T 832014

940.53'1-dc23 2014000772

Cover art: Actress-hostess Faye McKenzie jitterbugging with military guest; unknown aerial hostess and soldier to the left; and onlookers. By permission, Bruce Torrence, hollywoodphotographs.com.

Duke University Press gratefully acknowledges the Society of American Music, H. Earle Johnson Publication Subvention, which provided funds toward the publication of this book. 